\title{
DENSIDADE, TAXA DE ENTRADA E ANÁLISE MORFOLÓGICA DE PELLETS PLÁSTICOS NA PRAIA DE SANTA CRUZ DOS NAVEGANTES, GUARUJÁ - SP
}

\author{
Victor Vasques Ribeiro ${ }^{1}$ \\ ${ }^{1}$ Centro Universitário São Judas - Campus Unimonte. Rua Comendador Martins,52, CEP 11015-530, Santos,
} São Paulo.

\section{RESUMO}

A maior parte da matéria-prima utilizada em indústrias de plástico faz uso de pellets. Devido suas características, quando em ambientes aquáticos, grânulos plásticos podem concentrar e transportar diversos poluentes. A região da baía de Santos (SP) representa um local de grande importância para a economia, em função do Porto de Santos (SP). Neste estudo, a praia de Santa Cruz dos Navegantes, no município do Guarujá, localizada próxima à desembocadura do canal do porto de Santos foi amostrada. Com o objetivo de quantificar e analisar os pellets recentemente depositados foi calculado a taxa de entrada, densidade e análise morfológica destes grânulos. Para isso, foram realizadas cinco campanhas de coleta, de 7 a 11 de janeiro de 2019, direcionadas aos pellets presentes nos sedimentos superficiais da linha de deixa de maré durante picos de maré baixa. As densidades encontradas variaram entre 41,0 e 92,3 pellets $/ \mathrm{m}^{2}$ e a taxa de entrada foi entre $34,74 \mathrm{e} 71,10$ pellets/ $\mathrm{m}^{2}$. Essas maiores quantidades podem ser explicadas pelo fato de que a praia de Santa Cruz dos Navegantes recebe uma quantidade menor de banhistas e não tem limpeza de praia. Estes fatores fazem com que os pellets continuem presentes nos sedimentos superficiais. Foram encontrados pellets com oito formatos distintos, sendo os mais encontrados os cilíndrico achatado (28\%), esférico achatado (25\%) e disforme (24\%). O tamanho dos pellets encontrados foi, em maioria entre 3,0 e 4,0 milímetros, porém, foram encontrados grânulos entre 1,5 e 6,0 milímetros. Outros estudos da região encontraram quantidades maiores de grânulos cilíndricos e esféricos achatados e menos disformes. Essa descoberta elucida que a praia de Santa Cruz dos Navegantes recebe pellets degradados. Entretanto, esses pellets não foram degradados ao ponto de diminuir de tamanho. Palavras-chaves: Praia, Poluição, Microplástico.

\section{ABSTRACT \\ Density, intake, and morphological analysis of plastic pellets in Santa Cruz dos Navegantes beach, Guarujá - SP}

Most of the raw material used in plastic industries use pellets. Due to their characteristics, when in aquatic environments, plastic granules can concentrate and transport various pollutants. The region of the Bay of Santos (SP) represents a place of great importance for the economy, due to the port of Santos (SP). In this study, the beach of Santa Cruz dos Navegantes, in the city of Guarujá, located close to the mouth of the canal of the Port of Santos was sampled. In order to quantify and analyze the recently deposited pellets, the entry rate, density and morphological analysis of these granules were calculated. For this, five collection campaigns were carried out, from 7 to 11 January 2019, directed toward the pellets present in the superficial sediments of the higt tide line during low tide peaks. The densities found ranged from 41.0 to 92.3 pellets $/ \mathrm{m}^{2}$ and the entrance rate was between 34.74 and 71.10 pellets $/ \mathrm{m}^{2}$. These higher quantities can be explained by the fact that the beach of Santa Cruz dos Navegantes receives a smaller amount of bathers and does not have beach cleaning. These factors cause the pellets to remain present in the superficial sediments. Pellets were found with eight different formats, the most found being the flattened cylindrical (28\%), flat spherical $(25 \%)$ and Dysforme (24\%). The size of the pellets found was, in the majority between 3.0 and 4.0 millimeters, however, granules were found between 1.5 and 6.0 millimeters. Other studies in the region have found larger amounts of flattened cylindrical and spherical granules and less dysforms. This discovery elucided that the beach of Santa Cruz dos Navegantes receives degraded pellets. However, these pellets were not degraded to the point of decreasing in size.

Keywords: Beach, Pollution, Micro-plastic. 


\section{INTRODUÇÃO}

Os oceanos já foram considerados o berço da vida, mas hoje, sofrem com as ações antrópicas na Terra. A atual forma de consumo desenfreado praticado pela sociedade gera toneladas de lixo por dia espalhadas pelo mundo, e pela falta de um descarte final ambientalmente adequado, muitos materiais alcançam os mares, degradando a paisagem costeira e a vida marítima (Lima, 2012).

Um dos materiais mais encontrados nos mares e oceanos é o plástico. Esse material possui baixo custo de produção, peso reduzido, resistência e, além disso, apresenta a capacidade de ser moldado nas mais diversas formas e devido a essas características é utilizado por inúmeros setores da cadeia produtiva em todo o mundo (Araújo \& Costa, 2004; Amaral et al., 2011).

A grande variedade de produtos plásticos tem criado uma demanda por diferentes tipos de resinas, que possuem inúmeras composições e combinações, incluindo a criação e incorporação de aditivos, conforme a demanda do mercado. Existem dois principais tipos de resinas, que são classificadas de acordo com as características de fusibilidade: as resinas termoplásticas, que podem ser recicladas e as resinas termorrígidas, que não podem ser recicladas (EPA, 1992; Andrady, 2000; Piatti, 2005; Mano, 2010; Abiplast, 2015).

A forma mais comum de comercialização da matéria-prima de polímeros plásticos são os pellets, utilizados por indústrias para a produção dos mais variados objetos. Pellets podem ter várias formas, como esféricos e cilíndricos, com tamanhos de 1 a 5 milímetros e cores geralmente claras, brancas ou transparentes, dependendo de sua composição química e utilização final. Eles são componentes do lixo marinho, que é definido como qualquer resíduo sólido antropogênico descartado ou perdido, que tenha alcançado os oceanos e ambientes costeiros, incluindo itens dispostos nas praias, flutuando nos mares ou depositados no leito marinho (EPA, 1992; Cheshire et al., 2009; Abiplast, 2015).

A quantidade, formas e tipos de resíduos plásticos encontrados em praias arenosas estão diretamente interligados com os movimentos naturais como topografia, correntes e eventos de tempestades. Em praias arenosas, os pellets depositados tem distribuição espacialmente diferente no sentido longitudinal, assim como outros resíduos (Bowman et al., 1998; Gutiérrez et al. 2003; Storrier et al., 2007).

A maior concentração de pellets ocorre nas proximidades de grandes centros costeiros urbanos, industriais e de áreas portuárias, evidenciando que sua origem deve ser de fontes locais. Uma vez no ambiente, pellets podem ser transportados através da água da chuva, rios, mares e, desta forma, chegar a distâncias muito grandes do local de origem. Com o passar do tempo e a movimentação das ondas, estes grânulos sofrem degradação e desagregação, que ocorre devido à salinidade, temperatura e demais condições oceanográficas. Esses grânulos podem ser facilmente confundidos com alimento e, possivelmente interferir no ciclo reprodutivo de algumas espécies de animais (EPA, 1992; Ryan \& Swanepoel, 1995; Pelanda, 2007; Moura et al., 2011; Pereira, 2014).

Nos ambientes marinhos, a alteração das características químicas dos pellets faz com que esses grânulos se tornem vetores potenciais na transferência e exposição de organismos marinhos a poluentes. Os metais pesados, $\mathrm{PAH}$ e os poluentes persistentes orgânicos de elevada toxicidade (POPs), como o DDT, PCB e monofenóis são os poluentes adsorvidos mais estudados. A concentração desses poluentes em pellets pode ser um milhão de vezes maior do que quando dispersos na água. Em praias arenosas, esses poluentes adsorvidos aos pellets podem ser lixiviados na coluna de sedimentos (Endo et al., 2005; Ogata et al., 2009; Holmes et al., 2012; Fisner et al., 2013; Neto, 2014; Moreira et al., 2016; Alves et al., 2018).

A contaminação de ambientes aquáticos por pellets é uma questão urgente, dados os impactos dessas partículas na economia, harmonia paisagística e biodiversidade. Este estudo teve como objetivo a geração de dados de campo quanto à densidade, taxa de entrada e análise dos formatos e tamanhos dos pellets encontrados na praia de Santa Cruz dos Navegantes, no município do Guarujá (SP).

\section{MATERIAIS E MÉTODOS}

A Região Metropolitana da Baixada Santista, no estado de São Paulo, tem cerca de $2.422,776 \mathrm{~km}^{2}$ e é constituída por nove municípios: São Vicente, Praia Grande, Cubatão, Guarujá, Bertioga, Santos, Mongaguá, Itanhaém e Peruíbe, sendo Santos a cidade mais populosa (IBGE, 2013).

No Complexo Estuarino santista está presente o Canal do Porto de Santos. Localizado a sudoeste da ilha e às margens do estuário de Santos, o município do Guarujá. A praia de Santa Cruz dos Navegantes (Figura 1) foi o primeiro local do município de Guarujá visitado por exploradores portugueses em 1502. Também conhecida como "pouca farinha" o bairro de Praia Santa Cruz dos 
Navegantes proporciona ao turista conhecer o lado rústica da cidade, ao visitar a Fortaleza de Santo Amaro da Barra Grande (1598), patrimônio histórico do Brasil. $\mathrm{O}$ acesso ao bairro se dá apenas por via marítima a partir de embarcações ou pela estrada Santa Cruz dos Navegantes (Scarloto \& Pontin, 2011; SILVA, 2011; IBGE, 2013 apud Cafiero, 2017).

Com população estimada em 1.200 habitantes, o bairro Santa Cruz dos Navegantes está sujeito à ação das marés e das chuvas e abrange regiões de mangues e alagados. Os ecossistemas existentes neste local sofrem alterações impactantes, causados pela ocupação desordenada. Devido à falta de estrutura turística, coleta e tratamento, resíduos sólidos e esgoto doméstico não tratado alcançam a praia. A praia de Santa Cruz dos Navegantes tem 750 metros de extensão, sem ondas (Guimarães, 2008; Silva, 2011; Ferreira \& Lopes, 2013; OAB et al., 2015).

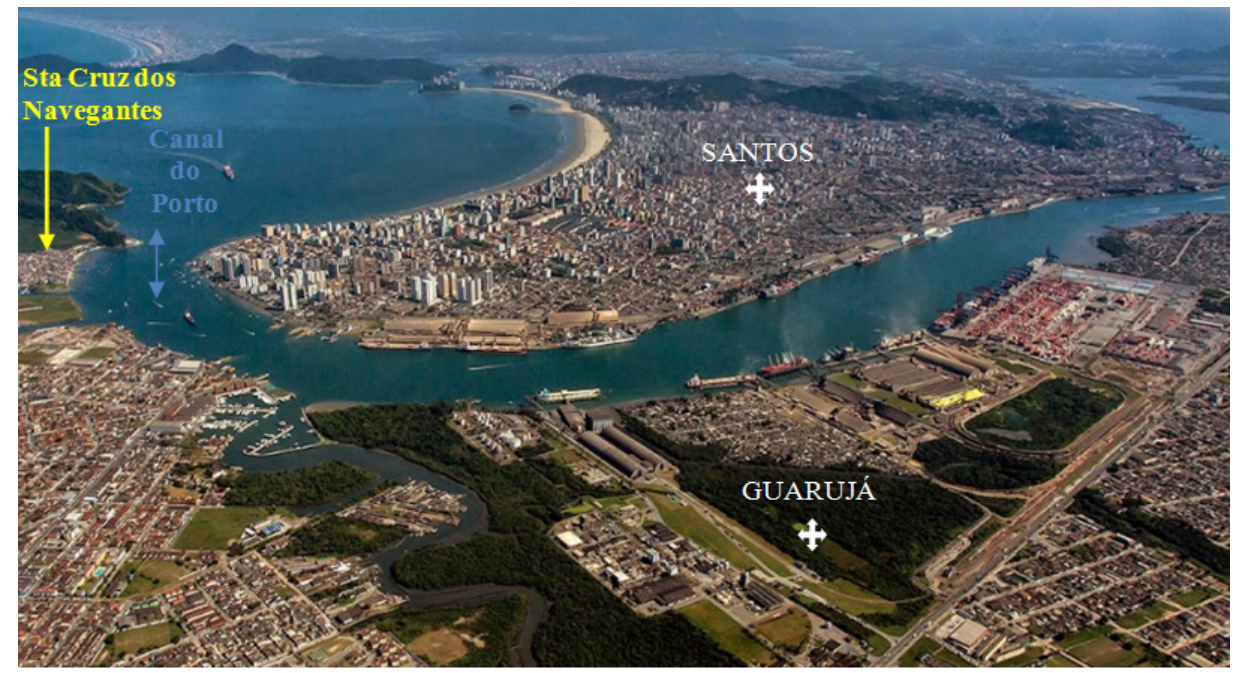

Figura 1. Vista aérea do bairro Sta Cruz dos Navegantes, dos municípios de Santos e Guarujá (SP), divididos pelo canal do porto (Adaptado de Dalmo Duque dos Santos, 2014).

Para alcançar os objetivos de calcular a densidade, taxa de entrada e analisar o formato e tamanho dos pellets coletados nesta praia em questão, foram realizadas neste estudo, coletas de amostras no período de 7 a 11 de janeiro de 2019 . Buscando encontrar os pellets que foram depositados recentemente no sedimento superficial, as coletas foram realizadas durante a maré baixa, ocasião na qual a zona de deixa de maré fique completamente exposta e a linha de deixa visível e temporariamente intocada pelas ondas.

A metodologia utilizada foi adaptada de Manzano (2009), Lima (2012), Gouvêa (2015) e Alves (2018). Foi identificado o ponto mais alto da zona da linha de deixa, na zona de deixa de maré. Um quadrante de 3 metros quadrados foi delimitado a cada dia de coleta, posicionado longitudinalmente a linha da costa, no qual foram recolhidos todos os pellets presentes na superfície dos sedimentos.

A densidade foi calculada ao dividir o número de grânulos encontrados por três, tendo então, o número de pellets por metro quadrado (pellets $/ \mathrm{m}^{2}$ ), para uma comparação mais assertiva com trabalhos realizados anteriormente nesta e em outras regiões. A taxa de entrada foi calculada a partir do intervalo de confiança da densidade média de pellets encontrados em todos os dias de coleta.

Para a realização da análise dos formatos e tamanhos, todos os pellets coletados nos quadrantes de três metros quadrados foram analisados. O tamanho dos grânulos foi determinado utilizando uma régua e auxílio de microscópios do Centro Universitário São Judas - Campus Unimonte, em Santos (SP). Os grânulos encontrados foram divididos em oito formatos distintos (Figura 2), sendo eles, a) retangular, b) cúbico, c) cilíndrico grosso, d) cilíndrico fino, e) cilíndrico achatado, f) esférico achatado, g) ovóide e, por último, h) disforme, que não se enquadra em nenhuma das anteriores, de acordo com Lima (2012). 


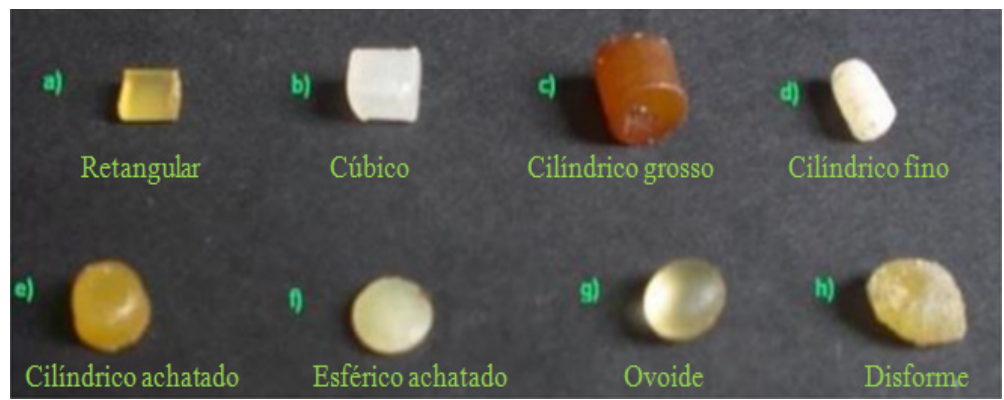

Figura 2. Formatos de pellets utilizados como base metodológica (Lima, 2012).

\section{RESULTADOS}

A densidade, ou seja, da quantidade de pellets por metro quadrado, na praia de Santa Cruz dos Navegantes está ilustrado na Tabela 1. A densidade total foi de 264,6 pellets $/ \mathrm{m}^{2}$. A maior densidade foi observada em 07 de janeiro de 2019 $\left(92,3\right.$ pellets $\left./ \mathrm{m}^{2}\right)$.

Tabela 1. Densidade diária, total e média de pellets na praia de Santa Cruz dos Navegantes (Arquivo pessoal, 2019).

\begin{tabular}{|c|c|}
\hline Dias de coleta & $\begin{array}{c}\text { Densidade } \\
\left(\text { pellets } / \mathbf{m}^{2} \text { ) }\right.\end{array}$ \\
\hline $07 / 01 / 19$ & 92,3 \\
\hline $08 / 01 / 19$ & 51,7 \\
\hline $09 / 01 / 19$ & 41,0 \\
\hline $10 / 01 / 19$ & 32,3 \\
\hline $11 / 01 / 19$ & 47,3 \\
\hline Densidade Total & 264,6 \\
\hline Densidade Média & 52,8 \\
\hline
\end{tabular}

Ao considerar o nível de significância de $95 \%$ e o resultado da densidade média durante os cinco dias de coleta, o intervalo de confiança da amostra foi de 18,18072565 . O intervalo pertinente à taxa de entrada de pellets na praia de Santa Cruz dos Navegantes foi entre 34,74 e 71,10 pellets $/ \mathrm{m}^{2}$ (Tabela 2).

Tabela 2. Taxa de entrada de pellets na praia de Santa Cruz dos Navegantes (Arquivo pessoal, 2019).

\begin{tabular}{c|c}
\hline Desvio padrão & 20,74188034 \\
\hline Tamanho da amostra & 5 \\
\hline Nível de significância & $95 \%(0,05)$ \\
\hline Intervalo de confiança & 18,18072565 \\
\hline Limite superior & 71,10 \\
\hline Limite inferior & 34,74 \\
\hline Taxa de Entrada $\left(\right.$ pellets $\left./ \mathbf{m}^{2}\right)$ & $34,74-71,10$ \\
\hline
\end{tabular}

Na Figura 1, observa-se a porcentagem da classificação de oito formatos de pellets encontrados. $\mathrm{O}$ formato esférico achatado teve a maior quantidade de pellets presentes na praia de Santa Cruz dos Navegantes, representando $28 \%$ da amostra. O formato cilíndrico achatado representa $25 \%$ dos pellets encontrados e os disformes, aqueles que não possuem formato identificável, $24 \%$.

Os outros formatos com menores incidências na praia em questão foram cilíndrico fino (8\%), seguido de cilíndrico grosso $(5 \%)$, retangular $(5 \%)$, cúbico $(3 \%)$ e ovoide $(2 \%)$.

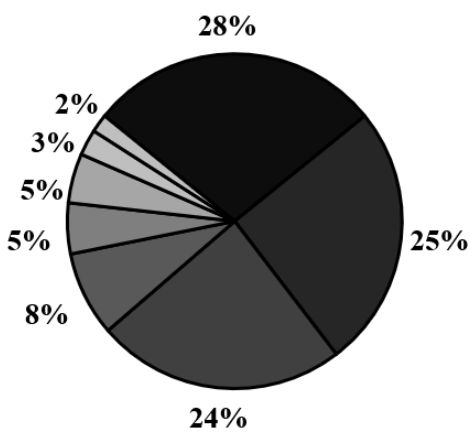

—Esférico Achatado

口Disforme

口Cilíndrico Grosso

口Cúbico

Figura 1. Formato de pellets $/ 3 \mathrm{~m}^{2}$ encontrados na praia de Santa Cruz dos Navegantes, Guarujá, São Paulo (Arquivo pessoal, 2019).

Dos 794 grânulos analisados neste estudo, o tamanho variou entre 1,5 e 6,0 milímetros. A maioria dos pellets encontrados media entre 3,5 e 4,0 milímetros, seguidos por grânulos de 3,0 e 4,5 milímetros. Foram encontrados grânulos de maiores 
dimensões, como 5,0 a 6,0 milímetros, e menores dimensões como 1,5 a 2,5 milímetros, porém, em menores quantidades (Figura 2).

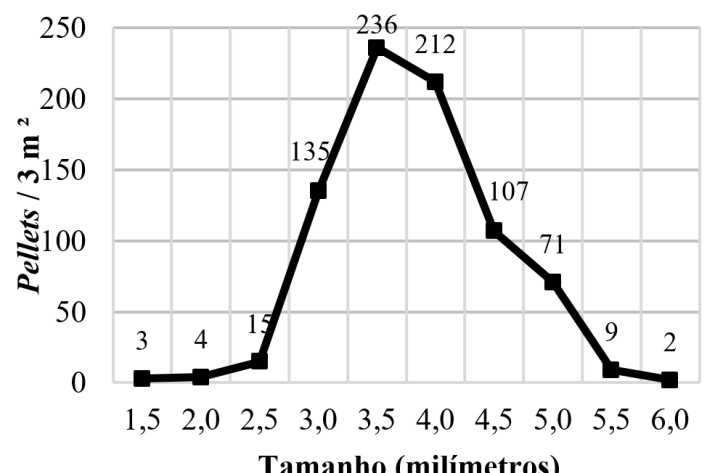

Figura 2. Tamanho de pellets $/ 3 \mathrm{~m}^{2}$ encontrados na praia de Santa Cruz dos Navegantes, Guarujá, São Paulo (Arquivo pessoal, 2019).

\section{DISCUSSÃO}

Pellets, em geral, apresentam uma densidade menor que a água do mar e, por isso, têm uma tendência a não serem soterrados. A estimativa da densidade de pellets nas praias pode estar subestimada por fatores como a proximidade de fontes emissoras, hidrodinâmica praial e condições meteoceanográficas, limpeza de praia e quantidade de banhistas, que ao se movimentarem na praia, podem soterrar e/ou prejudicar a visualização dos grânulos devido ao pisoteio. Quando as praias são mais "preservadas" os pellets são mais facilmente encontrados (Shiber, 1982; EPA, 1992; Shiber, 1987; Pianowski, 1997; Moore et al., 2001; Manzano, 2009; Alves, 2018).

Neste presente estudo, as densidades de pellets encontrados na praia de Santa Cruz dos Navegantes foram entre 41,0 e 92,3 pellets $/ \mathrm{m}^{2}$.

Manzano (2009) encontrou, nas praias de Santos e São Vicente (SP), uma densidade entre 5,0 e 100,0 pellets $/ \mathrm{m}^{2}$ durante o inverno e entre 3,0 e 58,0 pellets $/ \mathrm{m}^{2}$ durante o verão. Neste presente estudo, foi constatada uma densidade entre 41 e 92,3 pellets $/ \mathrm{m}^{2}$. Apesar de próximas, as praias de Santos e São Vicente (SP) e a praia de Santa cruz dos Navegantes, possuem características distintas. A quantidade de banhistas é bem maior em Santos e São Vicente, e ainda recebem limpezas diárias realizadas com veículos pesados, o que corrobora para o soterramento, e consequentemente, menor quantidade de pellets amostrados no sedimento superficial.

A menor distância de fontes emissoras costuma coincidir com uma maior quantidade de pellets amostrados. Gouvêa (2015), em Itanhaém (SP), encontrou uma densidade de 2,0 a 41,0 pellets $/ \mathrm{m}^{2}$ durante o inverno, primavera e outono. O município de Itanhaém está localizado a aproximadamente 81 quilômetros do porto de Santos, o que pode explicar as menores densidades encontradas.

Segundo Lima (2012), na praia do Tombo, localizada no outro lado do município do Guarujá, variando entre 8,0 e 145,0 pellets $/ \mathrm{m}^{2}$. A praia do Tombo recebe limpezas rotineiras e grandes quantidades de turistas e ainda assim, as densidades encontradas foram maiores que as deste presente estudo.

Segundo Alves (2018), são encontrados pellets em maiores quantidades nas praias localizadas mais próximas ao porto de São Sebastião, no litoral norte do estado de São Paulo. O porto de São Sebastião possui menores dimensões e capacidade, quando comparado ao de Santos, por isso, pode-se explicar uma densidade de pellets menor encontrada por Alves (2018), que foi de apenas 0,0 a 2,2 pellets $/ \mathrm{m}^{2}$.

Estes fatos indicam que, caso o porto de Santos (SP) seja considerados a fonte emissora de pellets, as praias ao redor servem como ponto inicial de deposição e distribuição, com um potencial para transportar estes grânulos para outras praias arenosas da região (Falcão, 2015).

A variação da taxa de entrada em praias de Santos e São Vicente (SP), calculada por Manzano (2009) durante o período de verão foi de 0,80 a 15,00 pellets $/ \mathrm{m}^{2}$. Lima (2012), na praia do Tombo, no município de constatou uma taxa de entrada média de 44 pellets $/ \mathrm{m}^{2}$. Verifica-se que, na praia de Santa Cruz dos Navegantes, a taxa de entrada é maior que em outras praias dos municípios de Guarujá, Santos e São Vicente. Este fato corrobora para a confirmação de que o porto de Santos, as correntes oceânicas e a quantidade de banhistas influenciam na distribuição e deposição de pellets ao longo da linha de deixa em praias da região.

Neste presente estudo, a porcentagem de pellets encontrados foi de $28 \%$ para o formato cilíndrico achatado, 25\% para cilíndrico achatado e $24 \%$ disformes. Assim como Shiber (1987), Pianowksi (1997) e Alves (2018), respectivamente em praias da Espanha, Rio Grande do Sul e litoral norte do estado de São Paulo, na região da baixada Santista, Manzano (2009) e Lima (2012) constataram que 
a maioria dos pellets encontrados foi do formato cilíndrico achatado. Segundo Gouvêa (2015), os grânulos mais encontrados foram do formato esférico achatado (Tabela 3 ).

Tabela 3. Porcentagens de formatos de pellets encontrados em praias arenosas paulistas (Arquivo pessoal, 2019).

\begin{tabular}{l|c|c|c}
\hline \multirow{2}{*}{ Estudo } & \multicolumn{3}{|c}{ Porcentagem de Formato } \\
\cline { 2 - 4 } & $\begin{array}{c}\text { Cil. } \\
\text { Ach. }\end{array}$ & $\begin{array}{c}\text { Esf. } \\
\text { Ach. }\end{array}$ & $\begin{array}{c}\text { Disfor- } \\
\text { me }\end{array}$ \\
\hline Manzano (2009) & 66,3 & 22,8 & 2,9 \\
\hline Lima (2012) & 66 & 7 & 3 \\
\hline Gouvêa (2015) & 12 & 65 & 12 \\
\hline Este estudo (2019) & 28 & 25 & 24 \\
\hline
\end{tabular}

Apesar de não fazer distinção entre os formatos cilíndricos finos e grossos, Alves (2018) encontrou mais pellets do formato cilíndrico em geral no litoral norte do estado de São Paulo. Em Itanháem, segundo Gouvêa (2015), a porcentagem de pellets disformes foi de $12 \%$, sendo esta, a maior encontrada considerando estes estudos da região. Na praia de Santa Cruz dos Navegantes, neste presente estudo, a porcentagem de grânulos disformes foi o dobro (24\%), o que pode significar que esta praia recebe maiores quantidades de pellets degradados.

Não é claro o tempo necessário para que um pellet perca sua forma visível, se tornando disforme. É possível que o grânulo seja transportado por grandes distâncias e por bastante tempo e ainda mantenha sua forma. Devido a este fato, não é possível afirmar que os pellets encontrados com formato visível na praia de Santa Cruz dos Navegantes $(76 \%)$ foram recentemente emitidos. Para que seja possível realizar a identificação precisa das fontes emissoras de pellets, é necessário comparar os formatos obtidos com outros fatores, como tamanho, deterioração, cor e presença de poluentes adsorvidos.

A presença de pellets de 1,5 milímetros foi baixa, com apenas três grânulos encontrados. Entretanto, mesmo com essa baixa presença, enquadramento dos pellets como pedregulhos finos não pode ser realizado, ou seja, enquadrados como sólidos entre 2,0 e 6,0 milímetros, conforme NBR 6502 (ABNT, 1995).

Desde a década de 70 até os dias atuais, 20 estudos brasileiros e mundiais que mediram os pellets coletados foram copilados (Gráfico 3). Destes, a maioria constataram pellets também entre 2,0 e 5,0 milímetros. Alguns estudos reportaram a presença de pellets com 1,0 a 1,5 e 5,0 a 6,0 milímetros. Poucos estudos relataram pellets maiores que 6,0 milímetros.
Observa-se que as dimensões podem chegar até 13,0 milímetros (Hays, 1974; Wong, 1974; Gregory, 1977; Shiber, 1979; Shiber, 1982; Wilber, 1987; Cruz et al., 1990; Shiber, 1991; EPA, 1992; Mato et al., 2001; Karapanagioti \& Klontza, 2007; Costa et al., 2009; Ivar do Sul et al., 2009; Manzano, 2009; Jayasiri et al., 2013; Kaberi et al., 2013; Neto, 2014; Gouvêa, 2015; Young \& Elliot, 2016; Haratsaris, 2018).

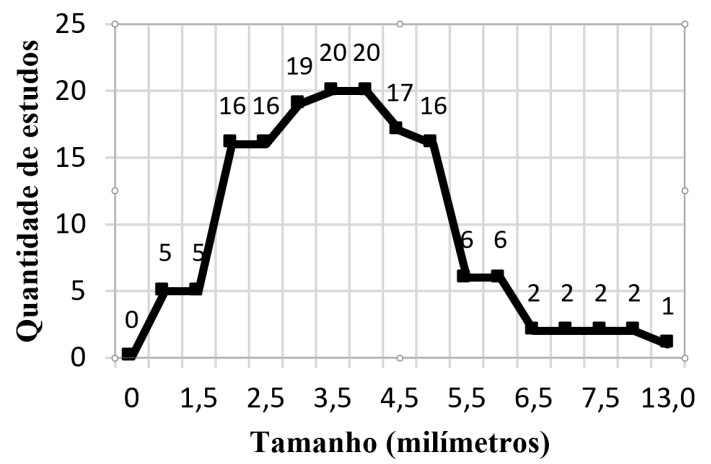

Gráfico 3. Tamanho de pellets segundo 22 estudos distintos (Arquivo pessoal, 2019).

Percebe-se um claro padrão entre os tamanhos 3,0 e 4,0 milímetros neste presente estudo. Fox Reciclagem afirmou que a extrusão de plásticos, isto é, a transformação da sucata em pellets, obtém um tamanho para os grânulos compreendidos entre 3,0 e 4,0 milímetros, uma vez que esse é considerado padrão, o que poderia explicar o fato de tais medidas serem as mais encontradas (Gouvêa, 2015).

Pellets encontrados em praias arenosas podem sofrer uma lenta degradação pela ação da areia, do sol e da água do mar, dando origem a fragmentos que, ao longo do tempo, se tornam cada vez menor. Esses grânulos podem sofrer degradação e, com isso, diminuir seu tamanho, atingindo medidas de 2,0 ou, até mesmo, 1,0 milímetro (Marlisco, 2013 apud Gouvêa, 2015). Neste estudo, a quantidade de pellets de 1,5 a 2,5 milímetros foi baixa, evidenciando que, a grande maioria dos pellets encontrados na praia de Santa Cruz dos Navegantes não sofreu degradação ao ponto de perderem suas características originais de produção. Este fato elucida que esses pellets podem ter sido perdidos ao meio ambiente recentemente.

Young \& Elliot (2016), que encontraram pellets com tamanho entre 1,0 e 8,0 milímetros em praias do Havaí, afirmam que a grande maioria dos pellets tinham dimensões entre 2,0 e 4,0 milímetros. 


\section{CONCLUSÃO}

A presença de pellets na praia de Santa Cruz dos Navegantes existe. A proximidade à fontes emissoras, hidrodinâmica praial e menor quantidade de banhistas faz com que a taxa de entrada de pellets seja significativa. Este trabalho corroborou para a afirmação de que as praias da região do porto de Santos (SP) recebem quantidades maiores de grânulos quando comparadas a outros portos, como o de São Sebastião (SP). As praias de regiões próximas ao porto de Santos podem servir como primeiro "obstáculo" ao transporte e deposição de pellets para regiões mais distantes.

O formato dos pellets encontrados teve altas quantidades de grânulos degradados. Entretanto, tamanho dos grânulos ficou, na maioria, entre o padrão de 3,0 e 4,0 milímetros. Para determinar o tempo de permanência destes grânulos no ambiente e suas respectivas fontes emissoras, é necessário aplicar metodologias complementares as utilizadas neste estudo.

\section{REFERÊNCIAS}

ABIPLAST. 2015. Os Plásticos. Disponível em: $<$ http://abiplast.org.br/site/os-plasticos>. Acesso em: 27/08/2018.

ABNT. 1995. NBR 6502 - Rochas e Solos. Disponível em: $<$ http://licenciadorambiental.com.br/wp-content/ uploads/2015/01/NBR-6.502-Rochas-e-Solos.pdf $>$. Acesso em 20 de janeiro de 2019.

ALVES, F. A. VIANA, E. UENO, H. M. SIMÕES, A. F. FONSECA, H. F. 2018. Caracterização de pellets plásticos em praias do litoral norte do estado de São Paulo. http://dx.doi.org/10.19177/rgsa. v7e12018300-314

AMARAL, G; JUNIOR, A. O. K; FRAGA, S. C. L. 2011. Guia ambiental da indústria de transformação e reciclagem de materiais plásticos. São Paulo: CETESB SINDIPLAST, p. 90.

ANDRADY, A. L. 2000. Plastics and their impacts in the marine environment. In: International Marine Debris Conference, Honolulu, Hawaii. Proceedings, p. 127-143.

ARAÚJO, M. C. B.; COSTA, M. 2004. Qualiquantitative analysis of the solid wastes at Tamandaré Bay, Pernambuco-Brasil. Trop. Oceanogr., v. 32, n. 2, p. 159-170.

BOWMAN, D.; MANOR-SAMSONOV, N.; GOLIK, A. 1998. Dynamics of litter pollution on
Israeli Mediterranean Beaches: a budgetary, litter flux approach. J Coast. Res., v. 14, n. 2, p. 418-432.

CAFIERO, M. F. C. 2017. Relações da comunidade da praia do Góes, em Guarujá (SP), com a natureza - extração e usos de recursos pesqueiros e vegetais. Universidade Santa Cecília. Disponível em : $<$ https:// unisanta.br/arquivos/mestrado/ecologia/dissertacoes/ Dissertacao_Maria_Carlota.pdf $>$. Acesso em: 29 de novembro de 2018 .

CHESHIRE, A. et al. UNEP/IOC Guidelines on Survey and Monitoring of Marine Litter. Regional Seas Reports and studies. Regional Seas Reports and Studies, $N^{\circ}$ 186; IOC Technical Series $N^{\circ} 83$, Nairobi: UNEP, 2009.

COSTA, M. F. DO SUL, I. J. A. SILVA-CAVALCANTI, J. S. ARAÚJO, M. C. B. SPENGLER, A. TOURINHO, P. S. 2009. On the importance of size of plastic fragments and pellets on the strandline: a snapshot of a Brazilian beach. Environ. Monit. Assess., v. 168, . 1- 4, p. $299-304$.

CRUZ, G. A. LÓPEZ, V. SOSA, C. 1990. Contaminación dos desechos sólidos llevados por corrientes marinas a la costa caribeña de Honduras. Revista de Biologia Tropical, 38(2A), p. 339-342.

ENDO, S. et al. 2005 Concentration of polychlorinated biphenyls (PCBs) in beached resin pellets: Variability among individual particles and regional differences. Marine Polluiton Bulletin v. 50, p. 1103-1114.

EPA. 1992. Plastics Pellets in the Aquatic Environment: Sources and recommendations. Environmental Protection Agency. Disponível em: $<$ http://www.globalgarbage.org/13\%20EPA $\% 20$ Plastic\%20Pellets.pdf $>$ Acesso em 16 de março de 2018.

FALCÃO, P. M. 2015. Panorama da poluição costeira por pellets de plástico em praias de SP (Brasil): uma contribuição aos estudos de geografia do litoral. Universidade de São Paulo. Disponível em: <http://www.teses.usp.br/teses/ disponiveis/8/8135/tde-12012016-150123/ publico/2015_PlinioMartinsFalcao_VOrig.pdf $>$. Acesso em 10 de junho de 2018.

FERREIRA, L. M. LOPES, M. A. 2013. Análise quali-quantitativa do lixo na praia de Santa Cruz dos Navegantes - Guarujá-SP-Brasil. Disponível em: <https://sites.unisanta.br/revistaceciliana/ edicao_09/8.pdf $>$. Acesso em 2 de fevereiro de 2019.

FISNER, M. TANIGUSHI, S. MAJER, A. P. BICEGO, M. C. TURRA, A. 2013. Concentration 
and composition of polycyclic aromatic hydrocarbons (PAHs) in plastic pellets: Implications for small-scale diagnostic and environmental monitoring. Marine Pollution Buletin, 76, 349-354.

GOUVÊA, C. S. C. 2015. Caracterização de pellets presentes na praia de Cibratel I, Itanhaém, e sua problemática no ambiente marinho. Centro de Ciências Biológicas e da Saúde. Universidade Presbiteriana Mackenzie.

GREGORY, M. R. 1977. Plastic pellets on New Zealand beaches. Mar. Pollut. Bull., v. 8, p. 82-84.

GUIMARÃES, A. R. S. 2008. Uso e significado de fitoterápicos em uma comunidade litorânea, município de Guarujá, SP. Universidade Católica de Santos. Disponível em: $<$ http://biblioteca. unisantos.br:8181/bitstream/tede/547/1/Adriana\%20 Guimaraes.pdf $>$. Acesso em 30 de janeiro de 2019.

GUTIERREZ, J. L., JONES, C. G., STRAYER, D. L., IRIBARNE, O. 2003. Molluscs as ecosystems engineers: the role of the shell production in aquatic habitats. Oikos, v. 101, p. 79-90.

HARATSARIS, V. M. 2018. PCBs e DDTs em grânulos de plástico depositados em praias do litoral paulista. Instituto Oceanográfico da Universidade de São Paulo. 10.11606/D.21.2019.tde-13022019141310 .

HAYS, H. \& CORMONS, G. 1974. Plastic particles found in tern pellets, on coastal beaches and at factory sites. Marine Pollution Bulletin 5: 44-6

HOLMES, A. TURNER, A. THOMPSON, R. 2012. Adsorption of trace metals to plastic resin pellets in the marine environment. Environmental Pollution, v. 160, p. $42-48$.

IBGE. 2013. Panaroma Santos (SP). Disponível em: <https:/cidades.ibge.gov.br/brasil/sp/santos/ panorama>. Acesso em: 21. out 2018.

IVAR DO SUL, J. A. SPENGLER, A. COSTA, M. F. 2009. Here, there and everywhere. Small plastic fragments and pellets on beaches of Fernando de Noronha (Equatorial Western Atlantic). Mar. Pollut. Bull., v. 58, p. 1229-1244.

JAYASIRI, H.B. PURUSHOTHAMAN, C.S. VENNILA, A. 2013. Quantitative analysis of plastic debris on recreational beaches in Mumbai, India. Mar. Pollut. Bull. 77, 107-112.

KABERI H, C. TSANGARIS, C. ZERI, G. MOUSDIS, A. PAPADOPOULOS, N. 2013. Microplastics along the shoreline of a Greek island
(Kea isl., Aegean Sea): types and densities in relation to beach orientation, characteristics and proximity to sources. ISBN: 978-960-6865-68-8, Mykonos island, Greece, June, p. 24-28.

KARAPANAGIOTI, H. K. \& KLONTZA, I. 2007. Investigating the properties of plastic resin pellets found in the coastal areas of Lesvos Island. Global Nest. J., v. 9, n.1, p. 71-76.

LIMA, G. H. 2012. Caracterização e taxa de entrada de pellets plásticos na praia do tombo do município de Guarujá - SP. Trabalho de conclusão de curso - Escola de Artes, Ciências e Humanidades, Universidade de São Paulo, São Paulo.

MANO; MENDES, E.; L. 2010. Introdução a Polímeros. 4 ed, Ed Bluncher. p. 191.

MANZANO, A. B. 2009. Distribuição, taxa de entrada, composição química e identificação de fontes de grânulos plásticos na Enseada de Santos, SP, Brasil. 124 f. Dissertação (Mestre em Ciências) Instituto Oceanográfico, Universidade de São Paulo, São Paulo.

MARLISCO. 2013. Impactes.

MATO, Y. HERNANDEZ-MILIAN, G. O'BRIEN, J. BERROW, S. O'CONNOR, I. OFFICER, R. 2001. Plastic resin pellets as a transport medium for toxic chemicals in the marine environment. Environmental science \& technology, v. 35, n. 2, p. 318-324.

MOORE, S. L., GREGORIO, D., CARREON, M., WEISBERG, S. B., LEECASTER, K. M. 2001. Composition and distribution of beach debris in Orange County, California. Disponível em: $<\mathrm{http} / / /$ ftp.sccwrp.org/pub/download/DOCUMENTS/Annu alReports/1999AnnualReport/09_ar10.pdf $>$. Acesso em 23 de janeiro de 2019.

MOREIRA, F. T., PRANTONI, A. L., MARTINI, B., DE ABREU, M. A., STOIEV, S. B., TURRA, A. 2016. Smallscale temporal and spatial variability in the abundance of plastic pellets on sandy beaches: methodological considerations for estimating the input of microplastics. Marine Pollution Bulletin $102,1,114$.

MOURA, C.M.; SILVA,E.V.; ROCHA, F. S. P.; PONTES-NETO, J. G.;MURRAY, F., COWIE, P.R. 2011. Plastic contamination in the decapod crustacean Nephrops norvegicus (Linnaeus, 1758). https://doi.org/10.1016/j.marpolbul.2011.03.032

NETO, A. G. F. 2014. Ocorrência, distribuição e grau de poluição por pellets, lixo de praia e lixo bentônico 
nas praias do município de Salvador, Bahia, Brasil. p. 101. Dissertação de mestrado apresentada junto ao programa de pós graduação em Geologia da Universidade Federal da Bahia, Salvador.

OAB. REINFRA. TRATA BRASIL. 2015. Pesquisa Saneamento Básico em Áreas Irregulares - Percepção dos Moradores. Disponível em: <http://www. tratabrasil.org.br/datafiles/estudos/areas-irregulares/ Saneamento-Basico-em-areas-irregulares-RelatorioMoradores-vf.pdf $>$. Acesso em 25 de janeiro de 2019.

OGATA, Y. et al. 2009. International pellet watch: global monitoring of persistent organic pollutants (POPs) in coastal waters. 1. Initial phase data on PCBs, DDTs and HCHs. Marine pollution bulletin, v.58, p. 1437-1346.

PELANDA, A. A. 2007. Impactos humanos sobre aves associadas a ecossistemas marinhas na costa paranaense. Universidade Federal do Paraná, p. 43.

PEREIRA, CABRAL, FLAVIA. 2014. Microplásticos no ambiente marinho: mapeamento de fontes e identificação de mecanismos de gestão para minimização da perda de pellets plásticos. Instituto Oceanográfico - Universidade de São Paulo. Disponível em: < http://www.teses.usp.br/teses/ disponiveis/21/21134/tde-30032015-150240/pt-br. php>. Acesso em 27 de janeiro de 2019.

PIATTI, T. M.; RODRIGUES, R. A. F. 2005. Plásticos: características, usos, produção e impactos ambientais. Maceió: EDUFAL, p. 51.

PIANOWSKI, F. 1997. Resíduos sólidos e esférulas plásticas nas praias do Rio Grande do Sul - Brasil, Universidade do Rio Grande. Disponível em: $<$ https://nema-rs.org.br/files/publicacoes/residuos. pdf>. Acesso em 20 de março de 2019.

RYAN, P. G.; SWANEPOEL, D. 1995. Updating marine debris research in South Africa. Mar. Debris Worldwide, v. 1, p. 6-7.
SCARLATO, C. F. \& PONTIN, A. J. 2011. Do nicho ao lixo: ambiente, sociedade e educação, $18^{\circ}$ ed., Ed. Atual: São Paulo, SP - Cap. 5, p. 57.

SHIBER, J. 1979. Plastic pellets on the coast of Lebanon. Marine Pollution Bulletin, 10 (1). pp 28- 30 .

SHIBER, J. 1982. Plastic pellets on Spain's 'Costa del Sol' beaches. Marine Pollution Bulletin, 13 (12). pp 409-412.

SHIBER, J. 1987. Plastic pellets and tar on Spain's Mediterranean beaches. Marine Pollution Bulletin, 18 (2). pp 84-86.

SHIBER, J. BARRALES-RIENDA, J. 1991. Plastic pellets, tar, and megalitter on Beirut beaches, 19771988. Environmental Pollution, 71 (1). pp 17-30.

SILVA, 2011. A poluição visual causada pelos quiosques na faixa de areia da praia da enseada - Guarujá. Disponível em: $<$ http://faculdadedondomenico.edu. br/revista_don/artigo7_ed4.pdf $>$. Acesso em 29 de janeiro de 2019.

STORRIER, K. L.; MCGLASHAN, D. J.; BONELLIE, S.; VELANDER, K. 2007. Beach litter deposition at a selection of beaches in the firth of forth, Scotland. J. Coast. Res., v. 23, p. 813-822.

WILBER, R. J. 1987. Plastic in the north Atlantic. Oceanus, v. 30, n. 3, p. 61-68.

WONG, C.S. GREEN, D.R. CRETNEY, W.J. 1974. Quantitative tar and plastic waste distributions in the Pacific Ocean. Nature 246:30-32.

YOUNG, A. ELLIOT, J. 2016. Characterization of microplastic and mesoplastic debris in sediments from Kamilo Beach and Kahuku Beach, Hawai'i. Marine Pollution Bulletin. 113. 10.1016/j. marpolbul.2016.11.009. 